\title{
Advantages and disadvantages of line and staff style of organizations
}

\section{Omolaja Muhammad 7}

\begin{abstract}
In the paper we discussed the fact that the dichotomous concepts of modern organizations exist in reality. We are focused on line and staff style of organizations because they are closely knitted. In line with this, their difference might not be easily identified by the laymen in organizational analysis and management. So, the main aim of our paper was to identify certain benefits from the knowledge of line and staff organizational analysis for modern managers as well as for employed people in an organisation. In the paper is concluded that the degree or extent of complexity, dependability, stability and adaptability of the technology and techno-structure of an organization will naturally dictate the way and manner the operations of the enterprise are distributed. By implication, the technology of an enterprise always dictates its span of control authority levels and extent of delegation, responsibility assignment, and number of steps along the ladder of responsibilities.
\end{abstract}

KEY WORDS: organization, staff and line managers, concepts of modern organizations

JEL: D02, J83, J24

UDC: 005.72:005.74

COBISS.SR-ID 219514124

\footnotetext{
${ }^{7}$ Corresponding author, International University, West Africa, Benin
} 


\section{Introduction}

In the modern industrial society, organizations exist in various forms. This phenomenon is inevitable because of the different approaches that are available for the study of organizations in the present time. Consequently, the common forms or classifications of modern enterprises are strictly formal organizations also described as formalism or mechanistic organizations, spontaneous growth organizations or informal organizations, and the modifications of these. Strictly formal organization using Louis Alien's words is a mechanism of well defined jobs, each bearing definite measures of authority, responsibility and accountability, the whole consciously designed to enable the people of the enterprise to work most effectively harmoniously together in accomplishing their goals.

The formal organization is characterized by being well-defined, bound by delegation, and relatively stable. It is a more or less arbitrary structure to which the individual must adjust for him to do certain things in a predestined manner, to obey orders from designated individuals, and to work cooperatively with others (Radović Marković,et al.,2009). Because of these arbitrary requirements, the formal organization tends to restrict and circumscribe the activities of individuals. It sets up boundaries, signposts, and pathways which must be followed.

\section{Specific characteristics of line and staff style of organization}

Line and staff style of organization is the mechanism involving division of work and labor and also specialization in such a way that there are line managers and staff managers. The line managers, in this case, have direct executive power, responsibility and authority to make sure that the right decisions are made at the right time and place. In line with this , most of the work in this field, however, has focused on describing the various ways in which managers can be subject to biases in their decision making (Cotarelo,2011).On the other hand, the staff managers necessarily provide specialized supporting or advisory services to the line managers in order to help them in the process of implementing their line decisions. This is the main reason while staff officers are said to be in an advisory and supportive positions in the contemporary organizations.

However, the basic line of demarcation between line and staff officers in an organization hinges on the decision making powers and authorities associated with their positions and roles. Hence, the line managers normally have the final executive power to make decisions but the power and authority of the staff line managers is limited to advisory status and subordinate to and also stem from that of the line managers. For illustration although it is the duty and responsibility of the production manager to determine the choice of machine, material and men combinations, the human resource manager may advise him probably on the psychological aspect of such combinations. 


\section{The concepts of line and staff organizations}

From this analysis it would be observed that line authority makes a manager to instruct subordinates on what to do. Here, authority flows vertically down through the structure. This is said to be a direct relationship between superior and subordinate officers, and also each subordinate is made responsible to only one person (i.e. unity of command). Again, a staff relationship subsists from the appointment of personal aids to senior members of staff. Such category of staff, however, usually have little or no direct authority in their own right except as an extension of their superior. This implies that except in situations where there is delegated authority and assignment of responsibility for some specific functions, there naturally exist no formal relationship between the personal assistant or aid and other staff members.

Other concepts that are related to the concepts of line and staff organizations are functional and lateral relationships. Functional relationships refer to relationship which subsists between people in advisory or specialist positions and between the managers and their subordinates. The specialist renders a common service to all divisions of the firm but has no direct authority over the people making use of the services. The specialist, however, has a line relationship with his own superior as well as the subordinate staff working with him.

Meanwhile, lateral relationships are the ones which subsist between people on the same level along the ladder of responsibility in the hierarchical structure of the enterprise but in different divisions or departments. Although such relationships may be formally defined in practice, they are of the informal type which are usually based on contact and consultation, and are necessary for the maintenance of coordination control and effective corporate performance in the organization.

In this context, there are certain benefits to be derived from the knowledge of line and staff organizational analysis.

These include the fact that (Radović-Marković, Omolaja, 2011):

1) Line and staff officers are able to direct and focus their attention jealously and judiciously to important and perhaps more strategic problems or decisions of management of the organization,

2) Line and staff officers are able to practice division of labor and specialization in which case experts and specialist staffs are encouraged, to handle the jobs which they can do better. This is somehow impossible in either strictly line or strictly staff organizations,

3) Line and staff style of organization relieves management of managerial overload for certain categories of duties and responsibilities which might otherwise be impossible to delegate to line subordinates at lower management levels within the hierarchical structure,

4) Line and staff style of organization brings about economies of scale into managerial mechanism. This is because the staff departments such as personnel or purchasing divisions make possible the concentration and centralization of supportive services that are, required by different sections and departments of the enterprise. 
On the other hand, line and staff dichotomy in modern organizations has some shortcomings including the following;

1) The system allows employees to receive specialist and expert information in the form of directives, instructions and advise through the line managers. This may however lead to the employees, misunderstanding or misinterpreting such information,

2) Line-staff dichotomy may lead to conflicts, friction and eventually confusion in an organization. This situation may in turn lead to instability, disunity, rivalry, unhealthily, competition and even disorderliness in the organization. This is because the goals of the line managers and staff managers are always different. Even where they succeed in establishing the same or similar goals, each of the officers may want to use different approaches or strategies to accomplish the goals. Line managers are often bitter staff personnel that meddle in their business. On the other hand, staffs personnel often complain that line managers do not accept their advice. There may even be some line managers who do not perform any definite function in an organization.

3) Line and staff dichotomy my split an operations or responsibility in such a way that it may becomes difficult do determine who should be praised or punished for good or bad performance, and

4) Line and staff dichotomy may lead to monopoly and arrogance among membership of the organization in which case one set of staff look down upon other category of staff. This may however lead to delay in operations and actions. For instance, the staff managers may delay or reschedule the performance of activities to suit its own convenience rather than the needs of the customer.

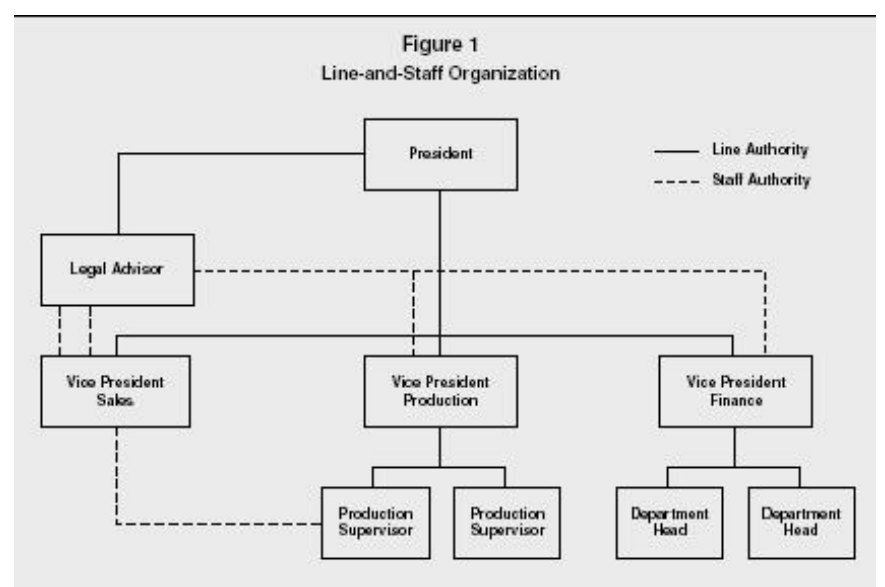

Figure 1:Line-and-Staff Organization

Source: Knotts, 2007 


\section{Conflict and unhealthy competition}

In the contemporary organizations, the conflict, friction and unhealthy competition that often erupt between line managers and their staff counterparts can be attributed to a number of factors including the following (Radović-Marković,Omolaja,2011):

1) The staff managers usually consider themselves as experts and specialists and hence, they feel that their opinions and contributions must be accepted, respected and implemented by line managers. Line managers tend to jetsam the suggestions and advice from the staff manager even though such ideas might be very useful just because the staff mangers in most cases claim the superiority of knowledge and experts when compared to their line counterparts,

2) Sometimes, the line managers may claim that their staff counterparts contribute no value to their product, rather, they are considered as meddlesome individuals who are just interested in the responsibilities of the line mangers,

3) Line managers are usually people of some matured age with a lot of experience and expertise. Hence, they do not morally take to the advice and suggestions from the staff mangers who are usually of lower ages and perhaps experience apparently for the age differentials,

4) Line mangers and their staff counterparts usually compete among themselves to be rewarded for good performance and also to shift blame over one another for unacceptable performance. This always lead to friction and conflict among them.

In the meantime, it must be noted that most of these conflicts and friction can be ironed out among the line and staff managers if:

1) The duties, responsibilities and areas of possible jurisdiction are specified for each position holder.

2) Accountability and responsibility mechanisms are clearly established and specified,

3) Individuals and groups within the organization are made to be aware what is expected of them and what is expected of the others perhaps through appropriate program of education and training of employees,

4) Positions are rotated and/or shifted among the line and staff office holders,

5) A general overseer, liaison officer or simply a coordinator may be appointed to coordinate and integrate the operations and functions of both the line managers and those arts. This would serve to unify and harmonize the, whose effort off the organization at the end.

\section{Conclusion}

Our practical experience for years as management consultant also offered significant input into this discussion. Throughout the text, our purpose had been to provide the readers with an understanding of the roles which a sound knowledge of modern management plays in organizations, irrespective of their scope or size, orientation, purpose and even sector in which they operate. In line with this, we can conclude that the structure adopted by any organization is completely dependent upon several factors. Among such variables are the 
origin and history of the enterprise its ownership and control structure, corporate and divisional resources, its goals operations or activities, its size and market coverage or scope, its stage and type of technology as well as its strategy and policy etc. To clarify these criteria, one would agree that the structure of an organization be it public and private, small or large, is dependents on its strategy and policy, and on whether it is a small company, a subsidiary of another giant one or a public sector organization. Also, the method or approaches by which an organization is structured and the reporting pattern adopted are all functions of the nature of the organization. These differences directly or otherwise affect the way and manner organizations are structured or arranged.

\section{References}

[1] Cotarelo ,J.L.(2011).HR discretion: understanding line managers' role in Human Resource Management

[2] Knotts,T.(2007). Line-And-Staff Organizations.In the Internet : ttp://www.referenceforbusiness.com/management/Int-Loc/Line-and-Staff-

Organizations.html

[3] Radović-Marković,M.,Omolaja,M.(2011). "Management dynamics in the new economy", VDM Verlag Dr. Müller, Saarbrücken, Germany, 404 pp.

[4] Radović-Marković ,M.(editor)(2011).Organizational behaviour and culture: globalization and the changing environment of organizations, VDM Verlag Dr. Müller, Saarbrücken,Germany. 348 pp

[5] Radović Marković,M. et.al. (editors) (2009).THE NEW ECONOMY : Challenges, Opportunities and Choices, I A Books ,Delhi, India. 385 pp.

\section{Article history:}

- $\quad$ Received 15 September 2015

- $\quad$ Accepted 20 October 2015 